\title{
Rapid serial visual presentation: degradation of inferential reading comprehension as a function of speed
}

\section{Francesco Di Nocera* and Orlando Ricciardi}

Department of Psychology, Sapienza University of Rome, Via dei Marsi 78, 00185 Rome, Italy

Email: dinocera@uniroma1.it

Email: orlando.ricciardi@uniroma1.it

*Corresponding author

\author{
James F. Juola \\ Department of Psychology, \\ Autonomous University of Madrid \\ Ciudad Universitaria de Cantoblanco, 28049 Madrid, Spain \\ Email: juolas@ku.edu
}

\begin{abstract}
There is increasing interest in the readability of text presented on small digital screens. Designers have come up with novel text presentation methods, such as moving text from right to left, line-stepping, or showing successive text segments such as phrases or single words in a RSVP format. Comparative studies have indicated that RSVP is perhaps the best method of presenting text in a limited space. We tested the method using 209 participants divided into six groups. The groups included traditional reading, and RSVP reading at rates of $250,300,350,400$, and $450 \mathrm{wpm}$. No significant differences were found in comprehension for normal reading and RSVP reading at rates of 250,300 and $350 \mathrm{wpm}$. However, higher rates produced significantly lower comprehension scores. It remains to be determined if, with additional practice and improved methods, good levels of reading comprehension at high rates can be achieved with RSVP.
\end{abstract}

Keywords: reading; rapid serial visual presentation; RSVP; comprehension; optimal speed rate; Spritz.

Reference to this paper should be made as follows: Di Nocera, F., Ricciardi, O. and Juola, J.F. (2018) 'Rapid serial visual presentation: degradation of inferential reading comprehension as a function of speed', Int. J. Human Factors and Ergonomics, Vol. 5, No. 4, pp.293-303.

Biographical notes: Francesco Di Nocera received his PhD in Psychology from the Sapienza University of Rome, Italy, where he currently serves as an Associate Professor of Work and Organisational Psychology in the Department of Psychology. He has contributed to the human factors literature with research studies on a variety of topics, including mental workload, human error, and adaptive automation. At the Department of Psychology, he coordinates the activity of the Eye-Tracking Laboratory. 
Orlando Ricciardi received his Master's in Work and Organisational Psychology from the Sapienza University of Rome, Italy, where he is currently enrolled in the $\mathrm{PhD}$ program in psychology and cognitive science. He is a member of the Eye-Tracking Laboratory, a facility of the Department of Psychology, where he is involved in several research tracks, including reading, vigilance, and mental workload.

James F. Juola received his PhD in Psychology from the Stanford University and has held professorships at the University of Kansas and Gettysburg College in the USA, Eindhoven University of Technology in The Netherlands, and the Autonomous University of Madrid in Spain. He has conducted research in the fields of psychophysics, attention, perception, cognition, human-technology interaction, and robotics.

\section{Introduction}

There has been increasing interest in the readability of text presented on digital screens at least since the 1980s (Chen et al., 1988; Cushman, 1986; Duchnicky and Kolers,1983; Dyson and Haselgrove, 2001; Juola, 1988; Juola et al., 1982; Kruk and Muter, 1984; Muter, 1996; Muter et al., 1982; Muter and Maurutto, 1991). Some authors have reported no important differences in the reading speed and comprehension of text in printed vs. electronic display formats (e.g., Muter et al., 1982). However, the increasing use of ever-smaller devices and displays, such as tablets, smartphones, smartwatches and bracelets, have challenged designers to come up with novel ways to present readable text in confined display areas. Moreover, the ubiquity of such devices and their internet connections have led to changes in reading habits, as more people are reading in unusual places and situations (e.g., standing in public transportation or in the dark). Even with such increases in reading opportunities, the abundance of new information continues to demand more time for reading, often exceeding the time we can allot for it. Often, reading online makes the reader vulnerable to time-wasting activities like browsing and mind wandering (Levitin, 2014; Lindquist and McLean, 2011; Risko et al., 2012, 2013; Szpunar et al., 2013) and interruptions (Foroughi et al., 2015). Such distractions decrease the ability to process relevant information when task requirements exceed the amount of time available for such processing (Hahn et al., 1992; Peters et al., 1984).

In anticipating both the abilities and limitations of electronic display media, researchers have compared a variety of display methods to determine which might be best for reading in different circumstances. These have included normal text pages or, when space is limited, a few words or phrases at a time. Additionally, it is possible to use dynamic text presentation methods, such as moving windows (in which participants hit a button to produce the next words of the text), moving text from right to left (called 'leading' or the 'times square' method), line stepping (moving text up one line at a time), or showing successive text segments such as sentences, phrases or single words in a rapid serial visual presentation (RSVP) format. The RSVP format consists of showing text as a sequential stream of words and was initially used as a controlled method for studying reading-comprehension processes (e.g., Forster, 1970; Forster and Ryder, 1971; Holmes and Forster, 1972; Potter, 1984). 
Studies that have directly compared reading comprehension levels across display methods have shown that RSVP is superior to the leading format (i.e., moving text from right to left in discrete jumps of one or more characters at a time; Granaas et al., 1984, Juola et al., 1995, although the method might be improved somewhat by making the movement more continuous; e.g., by moving the characters one pixel column at a time). Juola et al. (1982) found that the comprehension of short paragraphs was about the same using RSVP or a standard page format at comparable reading rates. Others (e.g., Rubin and Turano, 1994) have even demonstrated superiority for RSVP methods over standard pages in some circumstances. However, when reading rates are increased by shortening the length of each display in the RSVP format, reading comprehension decreases steadily when the presentation rate exceeds 250 wpm (e.g., Juola et al., 1982; Just and Carpenter, 1980; Potter, 1984; Potter et al., 1980).

\subsection{New RSVP applications}

Recently, a renewed interest has been shown in the RSVP technique due to a technical innovation called Spritz. Whereas conventional RSVP displays words either left-aligned or centred, Spritz use the optimal recognition point (ORP) (based on the fact that fixations in normal reading tend to be near the centre or slightly left of centre on most words, e.g., Rayner, 1979) to centre the word in an attempt to speed word recognition while reducing the need for eye movements (Maurer and Locke, 2014). Moreover, Spritz incorporates adjustments for punctuation, words, and phrases that require different processing times, with the aim of increasing comprehension at higher wpm rates while providing a better reading experience compared to simple RSVP.

Boo and Conklin (2015) tested Spritz efficacy in a recent study comparing detailed and inferential comprehension after reading texts on paper vs. a computer display using RSVP (inferential comprehension is the ability to understand the underlying meaning, or gist, of the text even when such information is not explicitly stated). The texts were no longer than 500 words and were presented in English at an imposed reading rate of 500 and $1000 \mathrm{wpm}$ for native and non-native speakers. Results showed that presenting text one word at a time did not impair inferential comprehension for both native and nonnative speakers when subjects read at $500 \mathrm{wpm}$, supporting Spritz efficacy. However, it is worth noting that the texts they used were no longer than 500 words, so the reader was committed for only one minute or less, and only five questions were used to assess comprehension. With a different approach, Benedetto et al. (2015) used a chapter of the ' 1984 ' novel by George Orwell and tested the effects of the two reading modalities on comprehension, visual fatigue, performance, task load, and ocular behaviour. Results showed no differences between the two reading modalities in inferential comprehension, whereas literal comprehension was lower for Spritz than for control-reading at a presentation rate of $250 \mathrm{wpm}$. The authors interpreted these results to suggest that inferential comprehension can compensate for the loss of detailed information at normal reading rates in the RSVP format. The questionnaire they used included fifteen literal and fifteen inferential questions, so it was more detailed than that used by Boo and Concklin. Benedetto et al. therefore provided important evidence about Spritz efficacy, although their results are limited to a relatively slow reading rate that is no faster than the average reading speed of a reader who reads a text with the aim of learning from it (Baccino, 2004). 
There is little evidence that reading with RSVP allows for faster than average reading with equivalent levels of comprehension. For this reason, Ricciardi and Di Nocera (2017) designed a study in which reading an online magazine article was tested at different RSVP rates, and the results were compared with those of control-reading. The results showed no (inferential) comprehension differences between the control-reading format and RSVP at a rate of $250 \mathrm{wpm}$, whereas reading with RSVP at a rate of $450 \mathrm{wpm}$ resulted in poorer text comprehension. This result partially confirms the study of Benedetto et al., because no differences were found at a slow reading rate, and are different than Boo and Concklin's, who found no differences in inferential comprehension between Spritz and control-reading. This difference could be due to differences in the length of the text used and to the number and difficulty of the comprehension questions asked.

It is still unclear how reading one word presented at a time affects comprehension, especially when presentation rates exceed the speed of normal reading. The aim of the present study is to determine the fastest word presentation rate at which comprehension is not significantly disrupted. The study compared different reading rate conditions in RSVP, namely $250,300,350,400$ and $450 \mathrm{wpm}$, using the same text and questionnaire used by Ricciardi and Di Nocera (2017). Our hypothesis is that comprehension scores and reading rates are inversely related (e.g., comprehension scores at $450 \mathrm{wpm}$ should be significantly lower than those obtained in a $250 \mathrm{wpm}$ condition, but intermediate rates should be found that do not significantly impair reading comprehension).

\subsection{Study: control-reading vs. RSVP rates of 250, 300, 350, 400 and $450 \mathrm{wpm}$}

The aim of the present study was to investigate the limit, in words per minute (wpm) reading rate that could be achieved for RSVP without affecting text comprehension. According to previous studies (Benedetto et al., 2015; Juola et al., 1982; Ricciardi and Di Nocera, 2017), an RSVP rate of $250 \mathrm{wpm}$ does not compromise comprehension abilities, whereas reading rates of $450 \mathrm{wpm}$ or more result in significant comprehensions difficulties. However, $250 \mathrm{wpm}$ is about equivalent to the rate of normal reading, so RSVP provides no improvement. After the introduction of Spritz in the RSVP paradigm, it is still unknown whether reading with good comprehension is possible at higher presentation rates, and if faster reading using the Spritz technology will result in higher levels of comprehension than that obtainable with traditional RSVP. The present study is designed to address the first of these points, because the most important question at this stage of the research program is to understand where the comprehension threshold lies. A comparison between Spritz and other RSVP variants could be made eventually after gaining knowledge about the specific nature of the relation between reading speed and comprehension.

\section{Materials and methods}

\subsection{Participants}

Two hundred and ten students $(130$ females, mean age $=23.8$ years, s.d. $=2.2)$ were recruited and given a one-point bonus for a course grade. All participants had normal or corrected-to-normal vision and were native Italian speakers. They were naïve as to the 
goals of the study, its methodology and the expected results. Participants were divided into six groups corresponding to the six experimental conditions. This research complied with the tenets of the Declaration of Helsinki and was approved by the Institutional Review Board at the Department of Psychology, Sapienza University of Rome. Informed consent was obtained from each participant.

\subsection{Apparatus}

The RSVP stream was implemented by using Spreed (http://signup.spreedit.com/), a plugin available from the Chrome browser. Spreed was developed from the Spritz program (Waldman et al., 2013), in which a nominal reading speed is determined a priori, but the actual rate is affected by factors such as word and sentence lengths (see Table 1). Longer words are displayed for proportionately longer periods of time, and the pauses inserted after sentences increase with sentence length (see Maurer et al., 2014, for further details). Text was presented through Spreed as a 60 pt. serif type font on a computer display in a rectangular box while participants sat at a distance of $70 \mathrm{~cm}$, with a horizontal visual angle of $1^{\circ}$. Screen size was 474 (horizontal) $\times 297$ (vertical) $\mathrm{mm}$ and screen resolution was set to $1,920 \times 1,080 \mathrm{px}$.

Table 1 Differences between RSVP nominal speed and Spritz actual rate

\begin{tabular}{lccc}
\hline $\begin{array}{l}\text { Presentation nominal } \\
\text { rates }\end{array}$ & $\begin{array}{c}\text { RSVP nominal speed } \\
\text { (min, sec) }\end{array}$ & $\begin{array}{c}\text { Presentation actual } \\
\text { rates }\end{array}$ & $\begin{array}{c}\text { Spritz effective speed } \\
\text { (min, sec) }\end{array}$ \\
\hline $250 \mathrm{wpm}$ & 23,13 & $195 \mathrm{wpm}$ & 29,30 \\
$300 \mathrm{wpm}$ & 19,20 & $230 \mathrm{wpm}$ & 24,57 \\
$350 \mathrm{wpm}$ & 16,35 & $265 \mathrm{wpm}$ & 21,51 \\
$400 \mathrm{wpm}$ & 14,30 & $305 \mathrm{wpm}$ & 19 \\
$450 \mathrm{wpm}$ & 12,53 & $344 \mathrm{wpm}$ & 16,50 \\
\hline
\end{tabular}

Note: The average time in control-reading condition was 25 minutes and 40 seconds (226 wpm).

\subsection{Stimuli}

We used two readings, one for practice (a 472-word article called 'Samantha Cristoforetti, 169 giorni nello spazio', published in the Italian online magazine 'Il Post', http://www.ilpost.it/2015/05/11/samantha-cristoforetti-foto-spazio/) and an experimental text (a 5804-word article entitled 'La fame a Milano', published in the online version of the Italian magazine 'L'Internazionale', http://www.internazionale.it/reportage/2015/03/ 03/milano-expo-poverta). We used the flesh reading ease test adapted to Italian (Franchina and Vacca, 1986) to determine the readability level for the experimental text. It obtained a score of 55, making it appropriate for students at the 10th to 12th grade levels.

\subsection{Experimental design and procedure}

Participants were randomly assigned to one of five experimental conditions in a between-subjects experimental design: control-reading $(\mathrm{N}=35)$, RSVP 250 wpm 
$(\mathrm{N}=35)$, RSVP 300 wpm $(\mathrm{N}=35)$, RSVP 350 wpm $(\mathrm{N}=35)$, RSVP 400 wpm $(\mathrm{N}=35)$ and RSVP 450 wpm $(\mathrm{N}=35)$.

Participants assigned to RSVP conditions first received the practice reading in the Spreed format, and then all participants read 'La fame a Milano' in the normal or RSVP format having been told to expect a comprehension test afterwards. The room and screen lighting conditions were held constant for all participants, and no pauses were allowed during the study.

\subsection{Questionnaire}

A questionnaire was created composed of 49 true or false questions of which 21 were true and 28 false. Each question pertained to a specific text range, averaging about 118 words. The question order was randomised to minimise guessing strategies based on temporal relations between the questions and text locations. A translation into English was made by the authors of the excerpt from 'La fame a Milano' (Hunger in Milan) by Giorgio Fontana that was used in the present study, and it is reported here: "Among the many problems in a metropolis, hunger is one of the most elusive. As a priority, the issue of getting a roof over the heads of everyone appears to be a necessity: if you sleep every night on a bench, obviously you are homeless; and to see people on the benches at night, alas, just take a walk in Milan. What about hunger? How can it be identified in the absence of immediately available forms, such as reports and images of food shortages in a poor country? With respect to the housing issue, so debated these days, malnutrition may appear a very dated theme, almost relegated to the nineteenth century. In Milan, you may expect to find people freezing to death, but not starving to death. Yet, the whole discourse on food is not insignificant, and at the same time it is traversed by different levels of complexity. There is the radical hunger of those who have almost nothing; that of those who have something, but not enough, or those who spend one or two days without anything in their stomachs; there is the hunger of retired people who can't make ends meet and queue for food distribution. There is the hunger of those who go to the bakery begging for something, and that of those who take the leftovers of the neighborhood market. But there is also the hunger of those who satiate with repetitive and poor-quality diets - the children of the poorest families, for example - thus contributing to the additional issue of hidden hunger, the undernutrition due to vitamin and mineral deficiencies."

Example questions related to the excerpt above were:

- The housing issue is more obvious than the hunger issue, in fact the number of people who have no accommodation is greater than people who cannot feed themselves.

- The term 'hidden hunger' refers to people who do not attend a soup kitchen either because they feel ashamed or because they are not informed about it.

In this case, the correct answer is 'false' for both questions.

In a previous study (Ricciardi and Di Nocera, 2017), we administered the questionnaire to 30 students (20 females and 10 males with mean age of 22.4 and an s.d. of 2.8) who had not read the passage. Their average score was $53 \%$ correct, close to the expected value of $50 \%$, so we were confident that the probability of guessing the correct answers in the present sample was close to chance. 


\section{Data analysis and results}

The mean proportions of correct comprehension question answers for each group are shown in Figure 1. The arcsin transformations of the proportions of correct responses were used as the dependent variable in an ANOVA design using condition ( $T$ vs. 250 wpm RSVP vs. 300 wpm RSVP vs. 350 wpm RSVP vs. 400 wpm RSVP vs. $450 \mathrm{wpm}$ RSVP) as the single factor. Results showed a significant effect of condition $\left(\mathrm{F}_{5,204}=7.65, p<0.001, \eta_{p}^{2}=.15\right)$, and the observed power was 0.99 .

Figure 1 Percent correct comprehension scores in the control condition (traditional reading) and at different RSVP speed conditions

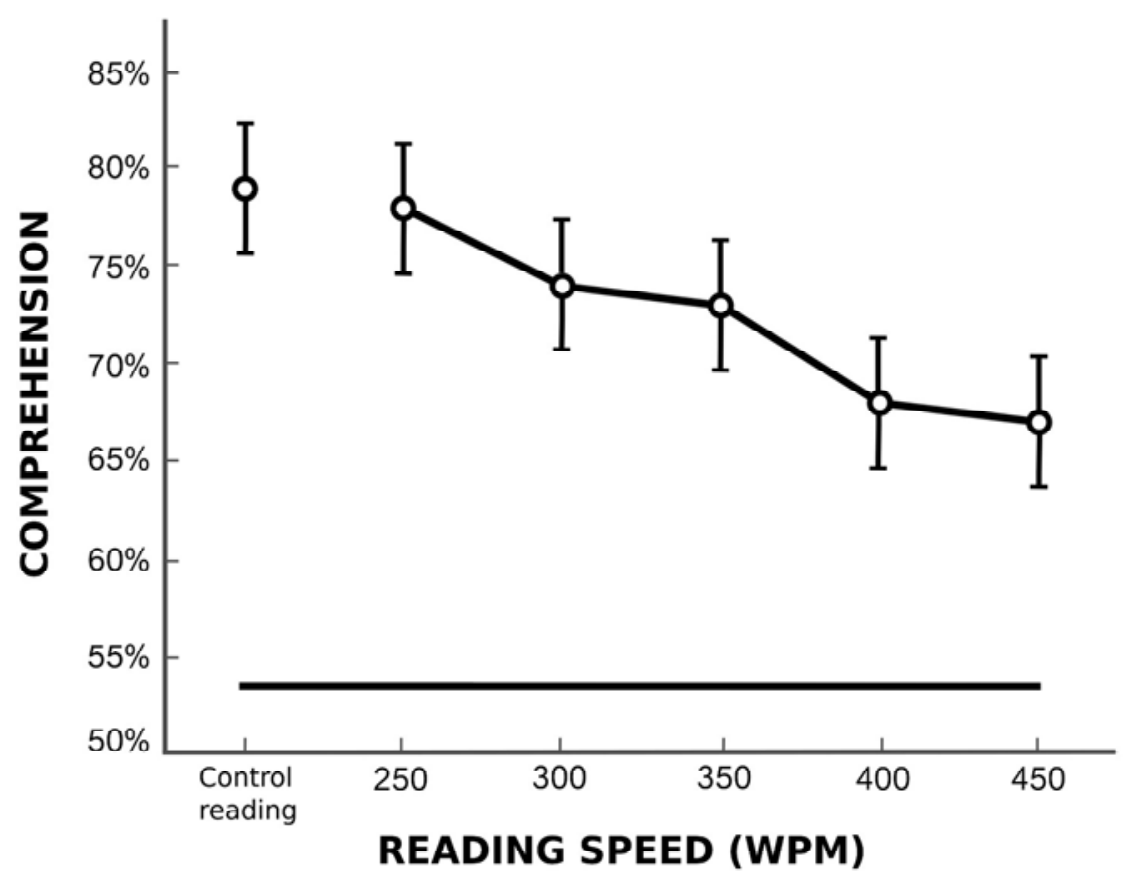

Notes: Vertical bars denote 0.95 confidence intervals. The straight horizontal line indicates the percent correct scores for participants who did not read the passage.

Post-hoc testing using the Bonferroni $t$ statistic showed no differences among comprehensions scores for control-reading and reading with RSVP at 250, 300 and $350 \mathrm{wpm}$, whereas there were significant differences when the presentation rate was 400 and $450 \mathrm{wpm}$. We also performed ANOVAs for single comparisons between groups in order to get estimates of the effect sizes. Results showed a significant difference between RSVP conditions at rate of 300 vs. $400 \mathrm{wpm}\left(\mathrm{F}_{1,68}=6.37, p=0.014, \eta_{p}^{2}=0.085\right)$, between control-reading condition and RSVP at rate of $300 \mathrm{wpm}\left(\mathrm{F}_{1,68}=5.43, p=0.023\right.$, $\left.\eta_{p}^{2}=0.074\right)$ and between control-reading condition and RSVP at rate of $350 \mathrm{wpm}$ $\left(\mathrm{F}_{1,68}=7.29, p=0.008, \eta_{p}^{2}=0.097\right)$. All other comparisons were not significant. It is important to note, however, that even though reading comprehension was significantly impaired at the two highest reading speeds used here, comprehensions scores were still 
significantly above those for the control-no reading condition, even for the $450 \mathrm{wpm}$ RSVP condition.

\section{Discussions and conclusions}

Many studies have investigated text readability on digital displays (Chen et al., 1988; Cushman, 1986; Duchnicky and Kolers, 1983; Dyson and Haselgrove, 2001; Juola, 1988; Kruk and Muter, 1984; Muter, 1996; Muter et al., 1982; Muter and Maurutto, 1991). Despite several results suggesting that reading in electronic display formats does not affect comprehension (e.g., Muter et al., 1982) the increasing use of ever-smaller devices has demanded novel ways to present readable text in confined display areas. Solutions proposed to solve this problem vary among different text presentation methods, such as moving text from right to left, line-stepping (scrolling text up one line at a time), or a RSVP format. Particularly, RSVP was selected for the present study as the best method of presenting text in a limited space based on previous research (e.g., Granaas et al., 1984; Juola et al., 1995).

The version of the RSVP format adopted for the present research is based on Spritz (Maurer and Locke, 2014), which is a technical innovation including modifications of the constant-rate, word-by-word method. That is, Spritz varies each word's location in the visual field to bring the optimal viewing position into central focus and modifies exposure times to account for things like word length and phrase structure as indicated by punctuation. However, it is still unknown if Spritz enables faster reading than simple RSVP at high presentation rates and acceptable levels of comprehension. Previous studies seem to indicate that reading RSVP displays at a rate of $250 \mathrm{wpm}$ do not compromise comprehension, whereas reading at $450 \mathrm{wpm}$ or more results in significant losses in comprehension ability (Acklin and Papesh, 2017; Benedetto et al., 2015; Ricciardi and Di Nocera, 2017).

The present study investigated the limits on reading speed that could be achieved for RSVP using the Spritz methodology without affecting text comprehension. With that in mind, we tested control-reading and RSVP reading at rates of 250, 300, 350, 400, and $450 \mathrm{wpm}$. The results showed a significant effect of condition, confirming the results found in a previous study (Ricciardi and Di Nocera, 2017). However, we performed single comparisons to determine the exact point at which the loss of comprehension was significant among RSVP conditions. Results clearly showed that an increase of $50 \mathrm{wpm}$ in presentation rate is not enough to determine a comprehension disruption, as single groups comparison were not different. A comprehension disruption was found when the presentation rate increased from 300 to $400 \mathrm{wpm}$, suggesting a measureable increase in reading difficulty occurs at a threshold of about $350 \mathrm{wpm}$. In particular, the proportions of correct answers on true-false comprehension questions declined steadily, producing monotonic declines in correct answer rates from normal reading at about $226 \mathrm{wpm}$ to RSVP rates of 250 to 450 wpm conditions. Although high RSVP rates seem to ease some problems associated with the need to make saccadic eye movements in normal reading (Rubin and Turano, 1994), increases in speed are likely to challenge later cognitive processes involved in comprehension, such as inference-making and memory consolidation. These results seems to indicate some limits in text comprehension using Spritz at presentation rates higher than $300 \mathrm{wpm}$, although comprehension was not 
eliminated at the higher rates, because performance was still better in the $450 \mathrm{wpm}$ condition than for the control-no reading group.

We are aware that this study is merely a first attempt to provide indications of the factors limiting reading comprehension at higher-than-normal reading speeds using the Spritz technology. Further studies need to be conducted that compare Spritz with other RSVP adaptations that have been developed specifically to optimise RSVP reading (e.g., Cocklin et al., 1984; Juola, 2018). Studies of the perceptual span have shown that more visual information can be processed in a single eye fixation than the one word presented at fixation in Spritz and most other RSVP methods (e.g., Legge et al., 2007). Therefore, further research should investigate how increased practice and improved methods could improve reading comprehension abilities at high rates using RSVP, thus providing useful applications for increasing the readability of text presented on small electronic displays and in a variety of other educational and work environments.

\section{References}

Acklin, D. and Papesh, M.H. (2017) 'Modern speed-reading apps do not foster reading comprehension', American Journal of Psychology, Vol. 130, No. 2, pp.183-199.

Baccino, T. (2004) La Lecture Électronique: De la vision à la comprehension, Presses Universitaires de Grenoble, Grenoble.

Benedetto, S., Carbone, A., Pedrotti, M., Le Fevre, K., Bey, LAY, Baccino, T. (2015) 'Rapid serial visual presentation in reading: the case of Spritz', Computers in Human Behavior, Vol. 45, pp.352-358, DOI: 10.1016/j.chb.2014.12.043.

Boo, Z. and Conklin, K. (2015) 'The impact of rapid serial visual presentation (RSVP) on reading by nonnative speakers', Journal of Second Language Teaching and Research, Vol. 4, No. 1, pp.111-129.

Chen, H.C., Chan, K.T. and Tsoi, K.C. (1988) 'Reading self-paced moving text on a computer display', Human Factors, Vol. 30, No. 3, pp.285-291.

Cocklin, T.G., Ward, N.J., Chen, H-C. and Juola, J.F. (1984) 'Factors influencing readability of rapidly-presented text segments', Memory and Cognition, Vol. 12, pp.431-442, DOI: 10.3758/BF03198304.

Cushman, W.H. (1986) 'Reading from microfiche, a VDT, and the printed page: subjective fatigue and performance', Human Factors, Vol. 28, No. 1, pp.63-73.

Duchnicky, R.L. and Kolers, P.A. (1983) 'Readability of text scrolled on visual display terminals as a function of window size', Human Factors, Vol. 25, No. 6, pp.683-692.

Dyson, M.C. and Haselgrove, M. (2001) 'The influence of reading speed and line length on the effectiveness of reading from screen', International Journal of Human-Computer Studies, Vol. 54, No. 4, pp.585-612, DOI: 10.1006/ijhc.2001.0458.

Foroughi, C.K., Werner, N.E., Barragán, D. and Boehm-Davis, D.A. (2015) 'Interruptions disrupt reading comprehension', Journal of Experimental Psychology: General, Vol. 144, No. 3, p.704, DOI: $10.1037 /$ xge0000074.

Forster, K.I. (1970) 'Visual perception of rapidly presented word sequences of varying complexity', Attention, Perception and Psychophysics, Vol. 8, No. 4, pp.215-221, DOI: 10.3758/BF03210208

Forster, K.I. and Ryder, L.A. (1971) 'Perceiving the structure and meaning of sentences', Journal of Verbal Learning and Verbal Behavior, Vol. 10, No. 3, pp.285-296, DOI: 10.1016/S00225371(71)80056-7.

Franchina, V. and Vacca, R. (1986) 'Adaptation of Flesch readability index on a bilingual text written by the same author both in Italian and English languages', Linguaggi, Vol. 3, pp.47-49. 
Granaas, M.M., McKay, T.D., Laham, R.D., Hurt, L.D. and Juola, J.F. (1984) 'Reading moving text on a CRT screen', Human Factors, Vol. 26, No. 1, pp.97-104.

Hahn, M., Lawson, R. and Lee, Y.G. (1992) 'The effects of time pressure and information load on decision quality', Psychology and Marketing, Vol. 9, No. 5, pp.365-378, DOI: 10.1002/ mar.4220090503.

Holmes, V.M. and Forster, K.I. (1972) 'Perceptual complexity and underlying sentence structure', Journal of Verbal Learning and Verbal Behavior, Vol. 11, No. 2, pp.148-156, DOI: 10.1016/ S0022-5371(72)80071-9.

Juola, J.F. (1988) 'The use of computer displays to improve reading comprehension', Applied Cognitive Psychology, Vol. 2, pp.87-95, DOI: 10.1002/acp.2350020108.

Juola, J.F. (2018) 'Give RSVP a chance: reply to Acklin and Papesh', American Journal of Psychology, Vol. 131, No. 2, pp.225-226.

Juola, J.F., Tiritoglu, A. and Pluenis, J. (1995) 'Reading text presented on a small display', Applied Ergonomics, Vol. 20, pp.227-229, DOI: 10.1016/0003-6870(95)00026-9.

Juola, J.F., Ward, N.J. and McNamara, T. (1982) 'Visual search and reading of rapid, serial presentations of letter strings, words, and text', Journal of Experimental Psychology: General, Vol. 111, pp.208-227, DOI: 10.1037/0096-3445.111.2.208.

Just, M.A. and Carpenter, P.A. (1980) 'A theory of reading: from eye fixations to comprehension', Psychological Review, Vol. 87, No. 4, pp.329-354, DOI: 10.1037/0033-295X.87.4.329.

Kruk, R.S. and Muter, P. (1984) 'Reading of continuous text on video screens', Human Factors, Vol. 26, No. 3, pp.339-345.

Legge, G.E., Cheung, S-H., Yu, D., Chung, S.T.L., Lee, H-W. and Owens, D.P. (2007) 'The case for the visual span as a sensory bottleneck in reading', Journal of Vision, Vol. 7, No. 2, p.9, pp.1-15, DOI:10.1167/7.2.9 [online] http://journalofvision.org/7/2/9/.

Levitin, D.J. (2014) The Organized Mind: Thinking Straight in the Age of Information Overload, Viking. New York.

Lindquist, S.I. and McLean, J.P. (2011) 'Daydreaming and its correlates in an educational environment', Learning and Individual Differences, Vol. 21, No. 2, pp.158-167, DOI: 10.1016/j.lindif.2010.12.006.

Maurer, M.S. and Locke, J. (2014) Why Spritz Works: It's All About the Alignment of Words [Web log post], 16 February [online] http://www.spritzinc.com/blog.

Maurer, M.S., Klein, M. and Waldman, F.A. (2014) US Patent Application No. 20140016867.

Muter, P. (1996) 'Interface design and optimization of reading of continuous text', in Cognitive Aspects of Electronic Text Processing, pp.161-180, Ablex, Norwood, NJ.

Muter, P. and Maurutto, P. (1991) 'Reading and skimming from computer screens and books: the paperless office revisited?', Behaviour and Information Technology, Vol. 10, No. 4, pp.257-266, DOI: 10.1080/01449299108924288.

Muter, P., Latrémouille, S.A., Treurniet, W.C. and Beam, P. (1982) 'Extended reading of continuous text on television screens', Human Factors, Vol. 24, No. 5, pp.501-508.

Orwell, G. (2004) 1984. Ebooks libres et gratuits.

Peters, L.H., O'Connor, E.J., Pooyan, A. and Quick, J.C. (1984) 'Research note: the relationship between time pressure and performance: a field test of Parkinson's law', Journal of Organizational Behavior, Vol. 5, No. 4, pp.293-299, DOI:10.1002/job.4030050406.

Potter, M.C. (1984) 'Rapid serial visual presentation (RSVP): a method for studying language processing', New Methods in Reading Comprehension Research, Vol. 118, pp.91-118.

Potter, M.C., Kroll, J.F. and Harris, C. (1980) 'Comprehension and memory in rapid sequential reading', Attention and Performance, Vol. 8, pp.395-418.

Rayner, K. (1979) 'Eye guidance in reading - fixation locations within words', Perception, Vol. 8, No. 1, pp.21-30.

Ricciardi, O. and Di Nocera, F. (2017) 'Not so fast: a reply to Benedetto et al. (2015)', Computers in Human Behavior, Vol. 69, pp.381-385, DOI: 10.1016/j.chb.2016.12.047. 
Risko, E.F., Anderson, N., Sarwal, A., Engelhardt, M. and Kingstone, A. (2012) 'Everyday attention: variation in mind wandering and memory in a lecture', Applied Cognitive Psychology, Vol. 26, No. 2, pp.234-242, DOI: 10.1002/acp.1814.

Risko, E.F., Buchanan, D., Medimorec, S. and Kingstone, A. (2013) 'Everyday attention: mind wandering and computer use during lectures', Computers and Education, Vol. 68, pp.275283, DOI: 10.1016/j.compedu.2013.05.001.

Rubin, G.S. and Turano, K. (1994) 'Low vision reading with sequential word presentation', Vision Research, Vol. 34, No. 13, pp.1723-1733.

Szpunar, K.K., Moulton, S.T. and Schacter, D.L. (2013) 'Mind wandering and education: from the classroom to online learning', Frontiers in Psychology, Vol. 4. DOI: 10.3389/ fpsyg.2013.00495

Waldman, F.A., Maurer, M.S. and Skrypnyuk, O. (2013) U.S. Patent Application No. 13/973,867. 